\title{
Drug Resistance Conferring Mutation and Genetic Diversity of Mycobacterium tuberculosis Isolates in Tuberculosis Lymphadenitis Patients; Ethiopia
}

This article was published in the following Dove Press journal: Infection and Drug Resistance

\author{
Sosina Ayalew $\mathbb{D}^{1,2}$ \\ Teklu Wegayehu ${ }^{2}$ \\ Hawult Taye (iD ${ }^{1}$ \\ Liya Wassie' \\ Selfu Girma $\mathbb{D D}^{\prime}$ \\ Stefan Berg ${ }^{3}$ \\ Adane Mihret'
}

'Armauer Hansen Research Institute, Addis Ababa, Ethiopia; ${ }^{2}$ Department of Biology, College of Natural Sciences, Arba Minch University (AMU), Arba Minch, Ethiopia; ${ }^{3}$ Bacteriology Department, Animal and Plant Health Agency, Weybridge, UK
Correspondence: Sosina Ayalew $\mathrm{Tel}+251912166324$

Email absosina20II@gmail.com
Background: Tuberculosis lymphadenitis (TBLN) is a growing public health concern in Ethiopia. However, there is limited information available on gene mutations conferring drug resistance and genetic diversity of $M$. tuberculosis isolates from TBLN patients.

Methods: Drug resistance and genetic diversity analysis were done on $91 \mathrm{M}$. tuberculosis isolates from culture positive TBLN patients collected between 2016 and 2017. Detection of mutations conferring resistance was carried out using GenoType MTBDRplus VER 2.0. Thereafter, isolates were typed using spoligotyping.

Results: Out of the 91 strains, mutations conferring resistance to rifampicin (RIF) and isoniazid (INH) were observed in two $(2.2 \%)$ and six $(6.6 \%)$ isolates, respectively. The two RIF resistant isolates displayed a mutation at codon 531 in the $r p o B$ gene with amino acid change of S531L. Among the six INH resistant strains, four isolates had shown mutation at the $K a t G$ gene at codon 315 with amino acid change of S315T, one isolate had a mutation at the inhA gene at codon 15 with amino acid change of $\mathrm{C} 15 \mathrm{~T}$ and one isolate had a mutation at the $i n h A$ gene with unknown amino acid change. All drug resistant isolates were from treatment naive TBLN patients. The dominantly identified Spoligo International Types (SITs) were SIT25, SIT149, and SIT53, respectively; these accounted for $43 \%$ of the total number of strains. The isolates were grouped into four main lineages; Lineage 1 (2, 2.2\%), Lineage 3 (38, 41.7\%), Lineage $4(49,53.8 \%)$ and Lineage $7(2,2.2 \%)$. Four out of six $(66.7 \%)$ isolates with drug resistance conferring mutations belonged to clustered strains (strains with shared SIT).

Conclusion: The detection of drug resistant conferring mutation in treatment naïve TBLN patients together with detection of drug resistant isolates among clustered strains might suggest resistant strains' transmission in the community. This needs to be carefully considered to prevent the spread of drug resistant clones in the country.

Keywords: drug resistant, genetic diversity, mutation, tuberculosis lymphadenitis

\section{Introduction}

Tuberculosis (TB) continues to be one of the most important public health problems, causing high morbidity and mortality, primarily in low- and middle-income countries. ${ }^{1}$ Globally the total TB incidence has declined by an average of $1.6 \%$ per year since $2000 .^{1}$ However, the reduction in the number of extrapulmonary TB (EPTB) cases has been slower, resulting in a proportionate increase in EPTB compared to pulmonary TB (PTB). ${ }^{2}$ EPTB represented $30 \%$ of all case of TB notified in Ethiopia, which is greater than the global average of $16 \%{ }^{1}$ TB lymphadenitis (TBLN) accounted for $80 \%$ of all EPTB cases reported in Ethiopia. ${ }^{3}$ 
Multidrug resistant (MDR)-TB, which is defined as being resistant at list for rifampicin (RIF) and isoniazid (INH), remains a public health problem in many parts of the world. ${ }^{1}$ Globally, half a million people developed MDR/RIF resistant $\left(\mathrm{RIF}^{\mathrm{R}}\right)$-TB in 2019. ${ }^{1}$ Ethiopia is one of 14 countries included in all three World Health Organization (WHO) high burden country lists for TB, TB/HIV, and MDR-TB. ${ }^{1}$ Together with an increasing number of drug resistant TBs around the world, the number of cases of primary MDR-TB with EPTB presentation is also going to rise. ${ }^{4}$ However, drug resistant EPTB is largely neglected and it does not receive specific attention in international control strategies. ${ }^{5}$ As a result, drug resistant isolates from EPTB are not well investigated, particularly in low-income countries.

The causative agents of TB are species of the Mycobacterium tuberculosis complex (MTBC) comprising of seven human adopted lineages (Lineage 1-7) which show biogeographic specificities in that the individual lineages are associated with particular geographic locations. ${ }^{6}$ Also, the MTBC includes species that are more commonly found in animals, but with zoonotic ability. ${ }^{7}$ Lineages 2, 3 and 4 are referred to as "modern" lineages, whereas Lineages 1, 5 and 6 are called "ancient". Lineage 7 is phylogenetically localized between ancient and modern lineages and considered as a premodern lineage. ${ }^{6,8,9}$ Although both modern and ancient lineages exist in Ethiopia, the modern lineages, particularly 4 and 3, are the most prevalent types. ${ }^{10,11}$

Mycobacterium tuberculosis (M. tuberculosis) is described as a clonal bacterium, with no known plasmid and does not engage in horizontal gene transfer. Consequently, drug resistance in M. tuberculosis is usually mediated by chromosomal mutations and rearrangements. ${ }^{12,13}$ Molecular studies identified katG and $r р о B$ as major targets conferring resistance of M. tuberculosis to INH and RIF respectively. Also, mutations in the regulatory region of the inhA operon, encoding a putative enzyme involved in mycolic acid biosynthesis, causes overexpression of the InhA protein, leading to INH resistance through a titration mechanism. ${ }^{14,15}$

Despite low genetic diversity in M. tuberculosis compared to other bacteria, the strain genetic background has been reported to plays a role in the global emergence of drug resistant TB. For instance, Beijing strains that belong to Lineage 2 have been frequently associated with drug resistance. ${ }^{16,17}$ Therefore, describing drug resistance conferring mutations in $M$. tuberculosis and their strain diversity circulating in a specific geographical area is important for both biological and epidemiological reasons. Although several studies conducted in Ethiopia assessed drug resistance patterns and genetic diversity of M. tuberculosis isolates from PTB patients, only limited data is available in the same regard from TBLN patients. With this background, this study aims to evaluate gene mutations conferring drug resistance and to further investigate variations among M. tuberculosis strains of TBLN patients.

\section{Methods}

\section{Study Setting}

This study was conducted using M. tuberculosis isolates retrieved from Armauer Hansen Research Institute (AHRI) laboratory biorepository that have been collected between 2016 and 2017 from Bishoftu, Gondar, Mekele and Hawassa in Ethiopia, as part of the Ethiopia Control of Bovine Tuberculosis (ETHICOBOT) study. Isolates were retrieved from culture positive Fine Need Aspirate (FNA) specimens collected from TBLN patients using a convenient sampling method. Clinical and demographic information for each isolate was retrieved from the ETHICOBOT study database using structured data extraction sheets.

\section{Drug Resistance Testing Using GenoType MTBDRplus VER 2.0}

RIF and INH resistance conferring mutation was detected using GenoType MTBDRplus VER 2.0. (Hain Life Science $\mathrm{GmbH}$, Nehren, Germany) according to the manufacturer's instruction. The test is based on DNA strip technology and has three steps: DNA extraction, amplification, and reverse hybridization. GenoType MTBDRplus VER 2.0 detects the absence and/or presence of wild type (WT) and/or mutant (MUT) DNA sequences within specific regions of three genes: the rро $B$ gene-gene (coding for the $\beta$-subunit of the RNA polymerase), for the identification of $\mathrm{RIF}^{\mathrm{R}}$; the kat $G$ gene (coding for the catalase peroxidase), for high level INH resistance $\left(\mathrm{INH}^{\mathrm{R}}\right)$; and the promoter region of the inhA gene (coding for the NADH enoyl ACP reductase), for low level $\mathrm{INH}^{\mathrm{R}}$. GenoType MTBDRplus included eight $r p o B$ WT probes, four rpoB MUT probes in positions of $r p o B$ MUT1 (D516V), rров MUT2A (H526Y), rрoB MUT2B (H526D) and rpoB MUT3 (S531L), one katG WT probe, two kat $G$ MUT probes with katG MUT1 (S315T1) and katG MUT2 (S315T2), two inhA WT probes and four inhA MUT 
probes with inhA MUT1 (C15T), inhA MUT2 (A16G), inhA

MUT3A (T8C) and inhA MUT3B (T8A). According to the manufacturer's recommendations, the missing of a WT probe or presence of a MUT probe were considered as resistant.

\section{Spoligotyping}

Spoligotyping was carried out as described by Kamerbeek et al. ${ }^{18}$ Spoligotype patterns of each strain were prepared in binary and octal format and entered into spoligotyping database SITVIT2 (http://www.pasteur-guadeloupe. fr:8081/SITVIT2/), which is an updated version of SITVITWEB. ${ }^{19}$ Strains matching a preexisting pattern in the database were identified with Spoligo International Type (SIT) number, otherwise considered as orphans or new. Run TBLineage online tools (http://tbinsight.cs.rpi.edu/run tb line age.html) was used to predict major $M$. tuberculosis lineages. $^{20}$ Nomenclature for lineage names and numbers were assigned as proposed previously. For instance, Lineage 1 (Indo Oceanic; IO), Lineage 3 (East African-Indian; EAI), Lineage 4 (Euro-American; EA) and Lineage 7 (Ethiopian). ${ }^{21,22}$

\section{Data Quality Assurance}

Standard operational procedures for all laboratory tests were employed uniformly throughout the study. PCR was carried out in three separate rooms for DNA extraction, PCR mix preparation and amplification using dedicated pipettes and sterile tips. Furthermore, DNA from $M$. bovis Bacille Calmette-Guerin and M. tuberculosis H37Rv were used as positive controls while DNA free water from Qiagen was used as a negative control in each batch of the test.

\section{Data Analysis}

Data were double entered to an Excel file format and statistical analysis was performed using SPSS version 20 (IBM Corp, Armonk, NY, USA). Descriptive statistics were used to depict the demographic variables. The Fisher exact was calculated to test the association between drug resistant conferring mutation and specific lineages of $M$. tuberculosis isolates. $\mathrm{P}$-value $\leq 0.05$ was considered statistically significant.

\section{Ethical Consideration}

Ethical approval was obtained from the AHRI/ALERT Ethics Review Committee. Since the entire repository data were anonymized, no personal identifiers were collected during data retrieval.

\section{Results}

\section{Demographic Data and Isolates Information}

A total of $91 \mathrm{M}$. tuberculosis isolates obtained from TBLN patients were included in this study, of which $54(59.3 \%)$ were from females and 37 (40.7\%) from males. The patients' mean age was 32 years with a range of 9-76 years (Table 1). Of the 91 isolates included in this study, 35 (38.5\%), 27 (29.7\%), $21(23.1 \%)$ and $8(8.8 \%)$ were collected from Bishoftu, Gondar, Mekele and Hawassa, respectively.

\section{Drug Resistant Conferring Mutation in Mycobacterium tuberculosis Isolates} Of 91 isolates tested for GenoType MTBDRplus VER 2.0, mutations conferring resistance to RIF and INH were observed in two $(2.2 \%)$ and six $(6.6 \%)$ isolates, respectively. Two $(2.2 \%)$ of them were MDR isolates. Of isolates with resistant mutations, two $(2.2 \%)$ were in the $r p o B$ gene, four $(4.4 \%)$ were in the $k a t G$ gene and two $(2.3 \%)$ were in the inh $A$ promoter region. In two $\mathrm{RIF}^{\mathrm{R}}$ isolates, mutation was observed at codon S531L indicated by missing of $r p o B$ WT8 probe with gain in $r p o B$ MUT3 probes. Four of the six $\mathrm{INH}^{\mathrm{R}}$ isolates had a kat $G$ mutation. In three of these isolates, the mutation was observed at codon S315T1 indicated by absence of $K a t G$ WT with gain in katG MUT1 whereas one isolate had a mutation at S315T2 indicated by the absence of $K a t G$ WT with gain of $K a t G$ MUT2. Mutations in the inhA promoter gene occurred in two $\mathrm{INH}^{\mathrm{R}}$ isolates. One of these isolates had a mutation at codon $\mathrm{C} 15 \mathrm{~T}$ which was indicated

Table I Demographic Characteristics of Study Participants from Different Places in Ethiopia, 2016-2017

\begin{tabular}{|l|l|l|}
\hline Variables & Frequency & Number \\
\hline Sex & & \\
Male & 37 & $40.7 \%$ \\
Female & 54 & $59.3 \%$ \\
\hline Age Group & & \\
$9-21$ & 30 & $32.9 \%$ \\
$22-31$ & 20 & $21.9 \%$ \\
$32-4 I$ & 6 & $6.6 \%$ \\
$42-5 I$ & 21 & $23.1 \%$ \\
$>5 I$ & 14 & $15.4 \%$ \\
\hline Patient Category & & \\
New Case & 71 & $78 \%$ \\
Retreatment & 17 & $18.7 \%$ \\
Unknown & 3 & $3.3 \%$ \\
\hline
\end{tabular}


by the omission of inhA WT1 and with the presence of the inhA MUT1 band. In one isolate inhA MUT1 band developed without missing the WT probe (Table 2). All drug resistant isolates were from treatment naive TBLN patients.

\section{Genetic Diversity in Mycobacterium tuberculosis Isolates}

Among the 91 spoliogotyped isolates, 82 (90.1\%) were classified into 28 different spoligotyping patterns according to the SITVIT2 database. The remaining 9 (9.9\%) isolates were not registered in the database and thereby seen as new or orphans' strains. The dominating identified SITs were SIT25, SIT149 and SIT53, each consisting of $19(20.9 \%), 11(12.1 \%)$ and $9(9.9 \%)$ isolates, respectively (Figure 1).

Lineage 3 (EAI) was the most prevalent lineage in Gondar (18/27, 66.7\%) and Mekele (11/21, 52.3\%), whereas Lineage 4 (EA) was the most prevalent lineage in Bishoftu $(27 / 35,77.1 \%)$ and Hawassa $(7 / 8,87.5 \%)$. Two strains belonging to Lineage 1 (IO) were isolated in this study, both of them were from Mekele (SIT726). Furthermore, two Lineage 7 (Ethiopian) isolates were identified, one from Mekele (SIT910) and one from Gondar (SIT1729). Overall, Lineage 3 and Lineage 4 were the most prevalent lineages identified in this study, each accounted for $41.7 \%$ (38/91) and 53.8\% (49/91), respectively. Whereas Lineage 1 and Lineage 7 were the least prevalent lineages, each accounted for $2.2 \%$ of the total isolates (Table 3 ).

Cluster analysis based on spoligotyping patterns showed that 63 isolates were grouped into 9 clusters; as one cluster consisted of 2-19 isolates. The clustering rate was $69.2 \%$. Statistically significant different rate of clustering observed between major MTBC lineages (Fisher's Exact test $=8.413 ; \mathrm{P}=0.017)($ Table 4$)$.

\section{Drug Resistance Conferring Mutation and} Mycobacterium tuberculosis Lineages

Isolates with drug resistance conferring mutations for any of the anti-TB drugs (RIF or INH), tested for by GenoType MTBDRplus, belonged to Lineage $3(50 \% ; 3 / 6)$ and Lineage $4(50 \% ; 3 / 6)$. However, an association between having antiTB drug conferring mutation and major M. tuberculosis lineages were not statistically significant (Fisher exact test: $1.355 ; \mathrm{p}>0.05)$. Four out of six $(66.7 \%)$ of the drug resistant isolates in this study belonged to a clustered strain (strains with shared SIT). Out of the three resistant strains of Lineage 3, one MDR-TB isolate with rpoB and KatG mutations was of SIT25, and two INH ${ }^{\mathrm{R}}$ isolates with inhA mutation had SIT26 and Orphan spoligotypes, whereas, among the resistant strains of Lineage 4, one MDR-TB isolate with $r p o B$ and $K a t G$ mutations was of SIT149, two $\mathrm{INH}^{\mathrm{R}}$ isolates with a $k a t G$ mutation were of SIT 50 and SIT 149 (Table 2).

\section{Discussion}

This study presented the magnitude of drug resistance conferring mutation and genetic diversity of $M$. tuberculosis strains that cause TBLN in Ethiopia. Among the 91 isolates included in this study, mutations conferring resistance to RIF, INH, and to both of these drugs (MDR-TB), were observed in $2(2.2 \%)$, $6(6.6 \%)$, and $2(2.2 \%)$ isolates, respectively. $2.2 \% \mathrm{MDR}$ prevalence in this study was comparable with previous studies reported from Ethiopia among TBLN $(1-4 \%)^{23-25}$ and PTB patients $(1-3 \%){ }^{25-27}$. The problem of MDR in TBLN patients should not be ignored and early diagnosis of drug resistance is crucial to avoid the devastating effect of MDR TB.

The two $\mathrm{RIF}^{\mathrm{R}}$ isolates identified in this study contained the S531L mutation in the rpoB gene, which is the most frequently reported $r p o B$ mutation in the Ethiopian strains, ${ }^{23,28-30}$ indicating the possible transmission of strains with similar types of mutations in the community. However,

Table 2 Mutations Identified in Isoniazid and Rifampicin Resistant M. tuberculosis Strains

\begin{tabular}{|c|c|c|c|c|c|}
\hline $\begin{array}{l}\text { Anti-TB } \\
\text { Drugs }\end{array}$ & Gene & $\begin{array}{l}\text { Pattern of Gene Mutations (WT/ } \\
\text { MUT) }\end{array}$ & $\begin{array}{l}\text { Amino Acid } \\
\text { Change }\end{array}$ & $\begin{array}{l}\text { Resistance } \\
\text { Pattern }\end{array}$ & SIT \\
\hline Rifampicin & $r p o B$ & AWT8/MUT3 & S53IL & $\mathrm{RIF}^{\mathrm{R}}$ & SITI49, SIT25 \\
\hline \multirow[t]{2}{*}{ Isoniazid } & KatG & $\begin{array}{l}\Delta \mathrm{WT} / \mathrm{MUTI} \\
\Delta \mathrm{WT} / \mathrm{MUT2}\end{array}$ & $\begin{array}{l}\text { S3I5TI } \\
\text { S3I5T2 }\end{array}$ & $\begin{array}{l}\mathrm{INH}^{\mathrm{R}} \\
\mathrm{INH}^{\mathrm{R}}\end{array}$ & $\begin{array}{l}\text { SIT I49, SIT25, SIT50 } \\
\text { SITI } 49\end{array}$ \\
\hline & $\operatorname{inh} A$ & $\begin{array}{l}\Delta \text { WTI/MUTI } \\
\text { ND/MUTI }\end{array}$ & $\begin{array}{l}\text { CI5T } \\
\text { unknown }\end{array}$ & $\begin{array}{l}\mathrm{INH}^{\mathrm{R}} \\
\mathrm{INH} \mathrm{I}^{\mathrm{R}}\end{array}$ & $\begin{array}{l}\text { SIT26 } \\
\text { Orphan }\end{array}$ \\
\hline
\end{tabular}

Note: SITI 49 and SIT25 were MDR strains (resistant to INH and RIF).

Abbreviations: $\Delta$, deletion; WT, wild type; MUT, mutant; ND, no mutation detected at wildtype probe; RIF $F^{R}$, rifampicin resistant; INH ${ }^{\mathrm{R}}$, Isoniazid resistant; SIT, spoligotype international types. 


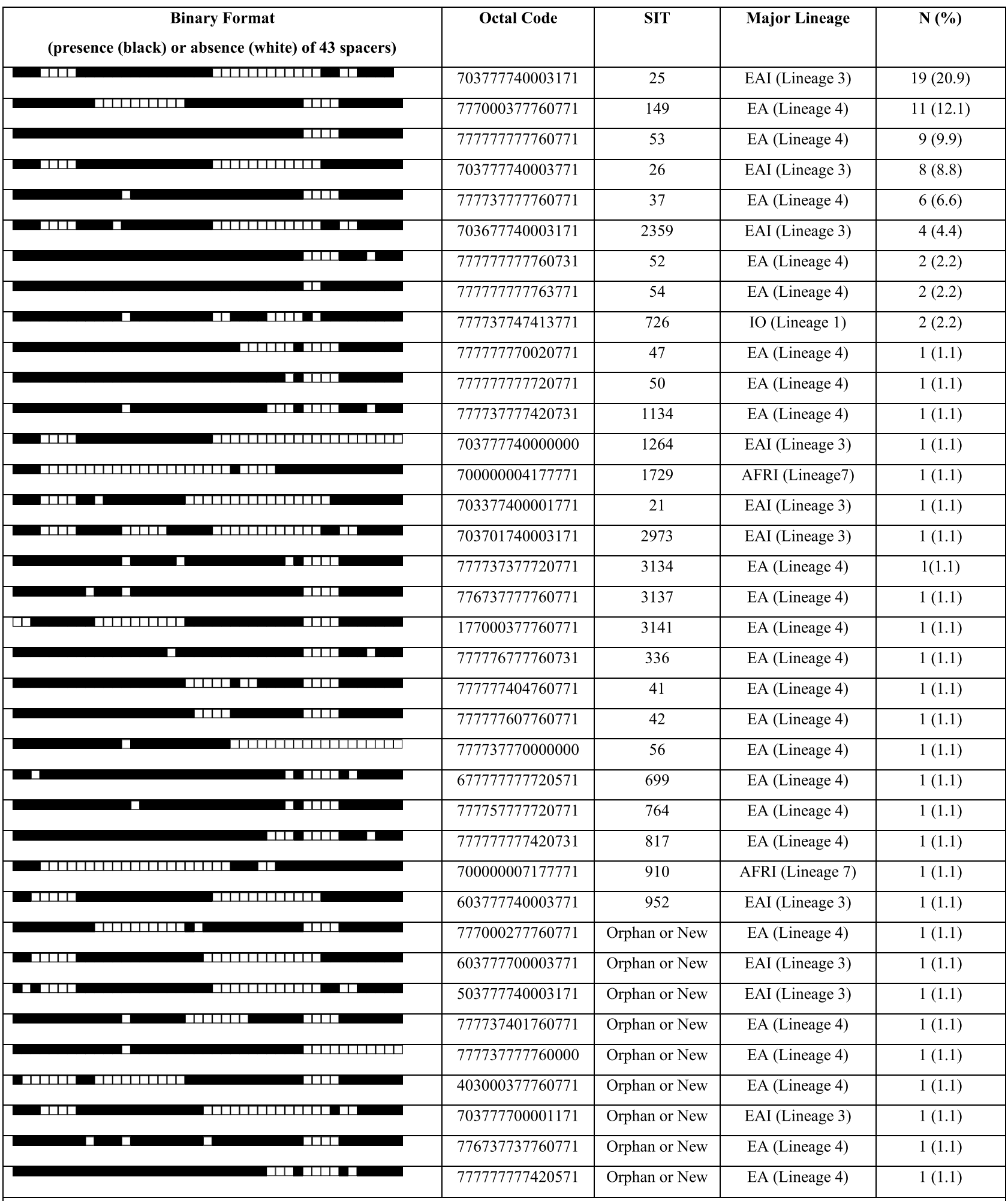

Key: SIT, Spoligo International Type; EA, Euro-American, IO; Indo-Oceanic; EAI, Euro American Indian; N, Number

Figure I Spoligotypes and major lineage classifications of clinical M. tuberculosis strains isolated from TBLN patients in different places in Ethiopia, 2016-2017.

mutations at other codons including H526D and D516V had also been reported among $\mathrm{RIF}^{\mathrm{R}}$ isolates. ${ }^{28-31}$ Both $\mathrm{RIF}^{\mathrm{R}}$ strains in this study were $\mathrm{INH}^{\mathrm{R}}$. Mono resistance to RIF is quite rare and almost all $\mathrm{RIF}^{\mathrm{R}}$ strains were also resistant to other drugs, especially to INH, which is why RIF $^{R}$ is considered as a surrogate marker for MDR-TB. ${ }^{15}$ 
Table 3 M. tuberculosis Lineage Distribution in Different Sample Collection Places in Ethiopia, 2016-2017

\begin{tabular}{|l|c|c|c|c|c|}
\hline Collection Site & Total Number of Isolates & LI N/\% & L3 N/\% & L4 N/\% & L7 N/\% \\
\hline Bishoftu & 35 & 0 & $8 / 22.8$ & $27 / 77.1$ & 0 \\
Gondar & 27 & 0 & $18 / 66.7$ & $8 / 29.6$ & $1 / 3.7$ \\
Mekele & 21 & $2 / 9.5$ & $11 / 52.3$ & $7 / 33.3$ & $1 / 4.8$ \\
Hawassa & 8 & 0 & $1 / 12.5$ & $7 / 87.5$ & 0 \\
Total no. of isolates/\% & $91 / 100$ & $2 / 2.2$ & $38 / 41.7$ & $49 / 53.8$ & $2 / 2.2$ \\
\hline
\end{tabular}

Abbreviations: N, number; L, lineage.

Resistance to INH is frequently associated with a mutation at two genes; kat $G$ and $i n h A$. In this study, $67 \%$ $(4 / 6)$ of $\mathrm{INH}^{\mathrm{R}}$ isolates had a katG gene mutation at codon $\mathrm{S} 315 \mathrm{~T}$. In contrast to this, $100 \%$ frequency of $\mathrm{KatG}$ mutation at codon $\mathrm{S} 315 \mathrm{~T}$ among $\mathrm{INH}^{\mathrm{R}}$ isolates had been reported from Ethiopia. $^{23,28,30,32}$ Moreover, in the current study, gene mutations attributed to low level $\mathrm{INH}^{\mathrm{R}}$ mainly caused by the mutations in the promoter region of inhA gene were also observed. Such mutations were more frequent in our study $(43 \%, 3 / 7)$ than the $10-12 \%$ reported by other studies conducted in Ethiopia, ${ }^{29,33}$ in Pakistan $(17 \%),{ }^{34}$ and in Switzerland (23\%). ${ }^{35}$ Mutations in inhA gene not only causes resistance to INH but also to the structurally related drug ethionamide, which shares the same target. ${ }^{14}$ Of the two isolates with inhA mutation, one of them had a mutation at C15T, whereas the other one had inhAMUT1 without mutation on the corresponding WT probe indicating heteroresistant isolates, ie concomitant infection with drug-resistant and drug-susceptible strains. TB infection with a heteroresistant M. tuberculosis population can be caused by infection with two different strains or the splitting of a single strain into susceptible and resistant organisms through microevolution. ${ }^{36,37}$ The relevance of heteroresistant TB should not be underestimated especially in highly endemic areas like Ethiopia, where there is a chance of co-infection with different $M$. tuberculosis strains with different resistant conferring mutations.

The M. tuberculosis population structure in this study was highly diverse and comprised of 28 different SITs and nine orphans or new strains. It is not unexpected, considering the samples are collected from different regions of the country. Lineage 3 and Lineage 4 were the most prevalent lineages identified in this study, each accounted for $41.7 \%$ and $53.8 \%$, respectively. Similar patterns of lineage distribution were reported from different regions of Ethiopia among EPTB $^{38-41}$ and PTB patients. ${ }^{26,30}$ Likewise, a study that analyzed the distribution of genotypes among PTB and TBLN patients in Ethiopia, reported a similar distribution of genotypes between the two manifestations of the disease. ${ }^{8}$ This may indicate the absence of pathogen-specific genetic factors associated with the high rate of TBLN in Ethiopia and also suggested a similar route of PTB and TBLN transmission in the community. Lineage 4 has a broad distribution in Europe and America, Africa and the Middle-East whereas Lineage 3 has a relatively narrow distribution occurring in East Africa and Central and South Asia. ${ }^{9}$

Table 4 Cluster Distribution Among Different Mycobacterium tuberculosis Lineages

\begin{tabular}{|c|c|c|c|c|c|c|}
\hline Lineage & Total Isolate & Cluster Strains & Cluster \% & Cluster Number & Cluster Size & SIT Number \\
\hline LI & 2 & 2 & $100 \%$ & I & 2 & SIT 726 \\
\hline L3 & 38 & 31 & $81.5 \%$ & 3 & $\begin{array}{l}19 \\
8 \\
4\end{array}$ & $\begin{array}{l}\text { SIT } 25 \\
\text { SIT } 26 \\
\text { SIT } 2339\end{array}$ \\
\hline L4 & 49 & 30 & $61.2 \%$ & 4 & $\begin{array}{l}11 \\
9 \\
6 \\
2 \\
2\end{array}$ & $\begin{array}{l}\text { SIT I49 } \\
\text { SIT } 53 \\
\text { SIT } 37 \\
\text { SIT } 54 \\
\text { SIT } 52\end{array}$ \\
\hline
\end{tabular}

Abbreviations: AHRI, Armauer Hansen Research Institute; EPTB, extrapulmonary tuberculosis; ETHICOBOTs, Ethiopia Control of Bovine Tuberculosis; INH, isoniazid; $\mathrm{INH}^{\mathrm{R}}$, isoniazid resistant; MDR, multidrug resistant; MTBC, Mycobacterium tuberculosis complex; MUT, mutant; PTB, pulmonary tuberculosis; RIF, rifampicin; RIR ${ }^{\mathrm{R}}$, rifampicin resistant; TB, tuberculosis; TBLN, tuberculosis lymphadenitis; SIT, Spoligo International Type; WHO, World Health Organization, WT; wild type. 
Lineage 1 and Lineage 7 were the least prevalent lineages in this study, each accounted for $2.2 \%$ of the 91 TBLN isolates, which is in line with the overall relatively low prevalence of these lineages in Ethiopia. ${ }^{10,11}$ Lineage 1 is found in areas around the Indian Ocean and the Philippines. $^{9}$ The Lineage 1 isolates (two isolates) in this study were isolated from Mekele TBLN patients. Previously, Lineage 1 was also reported from Southern, ${ }^{8,42}$ Central $^{39}$ and North Ethiopia. ${ }^{32,43}$ The two Lineage 7 isolates identified in this study were isolated from Mekele and Gondar TBLN patients. This is the newly identified lineage initially reported in higher frequency from Woldia in Northern Ethiopia. ${ }^{8}$ Since then, it has been reported from different regions of the country. ${ }^{38,40,44,45}$ Lineage 7 has also been reported among Ethiopian immigrants in Djibouti and the Netherlands. ${ }^{46,47}$ The reason why Lineage 7 is restricted to native Ethiopians and Ethiopian immigrants is not yet well understood but it has been indicated that Lineage 7 has a lower rate of progression towards disease relative to other lineages, with subsequent out competition by other M. tuberculosis lineages. ${ }^{44}$ That may explain the geographical restriction of Lineage 7 to Ethiopia. Lineage 7 has contributed to the rejection of the "virgin soil" hypothesis of human TB in sub-Saharan Africa. According to "virgin soil" hypothesis, TB in the African region was due to European contact during the colonial period as it was originally free of TB. ${ }^{48}$

In our study, the overall clustering rate (strains with shared SIT) was $65.6 \%$ which is in line with other studies conducted in Ethiopia. ${ }^{8,26,41,49}$ A high rate of clustering maybe indicates active transmission of the disease and an ineffective TB control programme in the country. However, the low discrimination power of spoligotyping should be considered. ${ }^{50}$

The majority $(4 / 6,66.7 \%)$ of isolates with drug resistant conferring mutations in this study belonged to clustered strains, suggesting the possibility of transmission of drug resistant isolates between patients in the country. Moreover, all drug resistant isolates identified in the current study were from treatment of naïve TBLN patients. That supports exposure of the patients to drug resistant M. tuberculosis strains in the community, rather than susceptible strains becoming resistant during the TB treatments. This needs to be carefully considered to prevent the spread of drug resistant clones in the country. Of the six isolates with drug resistant conferring mutations, two (33\%) of them were SIT 149 whereas the rest were SIT 25,
SIT 26, SIT 50 and one orphan strain. The high frequency of SIT149 among drug resistant M. tuberculosis isolates has been previously reported in Ethiopia. ${ }^{51,52}$ However, Bereket et al indicated that the observed association between SIT149 and the development of drug resistance may not necessarily indicate that the stains are prone to be drug resistant but could rather be association consequences of their high prevalence in the population. ${ }^{25}$

No significant associations were found between a particular lineage and any drug resistant conferring mutation. However, this might have been due to the low sample size. Apart from results shown for Lineage 2, ${ }^{16,17}$ the association between different $M$. tuberculosis lineages and TB drug resistance is rather inconsistent. For instance, Biadglegne et $\mathrm{al}^{40}$ and Tadesse et $\mathrm{al}^{38}$ showed a significant association between drug resistance and Lineage 3, whereas Amir et al found an association between Lineage 4 and drug resistance conferring mutations. ${ }^{32}$ In contrast, other studies did not find associations between the genotype of $M$. tuberculosis isolates and their drug resistance pattern. ${ }^{53,54}$ This shows that there is uncertainty on the strain-specific propensity for the acquisition of drug resistance conferring mutation among $M$. tuberculosis isolates. More work needs to be done to define whether some M. tuberculosis genotypes are more prone than others to develop drug resistance.

\section{Conclusion}

Overall, although the sensitivity of the GenoType MTBDRplus assay to detect strains with a novel mutation or gene mutation outside the resistance determining region is limited, the present study demonstrated the feasibility of estimating the magnitude of gene mutations conferring drug resistance and genetic diversity of drug resistant M. tuberculosis isolates in TBLN patients. Lineage 3 and Lineage 4 were the most prevalent lineage types identified in this study with high clustering rates of SIT 25, SIT149 and SIT 53. A drug resistant conferring mutation was detected among clustered strains, which could suggest clonal resistant strains transmission in the community. However, the tool we used to characterize the different M. tuberculosis strains, spoligotyping, is prone to convergent evolution and has low resolution power for cluster analysis. This warrants the need for future studies with a better tool of discrimination power like whole-genome sequencing (WGS) to understand the transmission dynamics of drug resistant TB and strengthen the control programs of TBLN in Ethiopia. 


\section{Acknowledgments}

We would like to thank study participants for taking part in the study and all members of the ETHICOBOTS project who had a great contribution to the success of this study. The members of the ETHICOBOTS consortium are: Abraham Aseffa, Adane Mihret, Bamlak Tessema, Bizuneh Belachew, Eshcolewyene Fekadu, Fantanesh Melese, Gizachew Gemechu, Hawult Taye, Rea Tschopp, Shewit Haile, Sosina Ayalew, Tsegaye Hailu, all from the Armauer Hansen Research Institute, Ethiopia; Rea Tschopp from the Swiss Tropical and Public Health Institute, Switzerland; Adam Bekele, Chilot Yirga, Mulualem Ambaw, Tadele Mamo, Tesfaye Solomon, all from the Ethiopian Institute of Agricultural Research, Ethiopia; Tilaye Teklewold from the Amhara Regional Agricultural Research Institute, Ethiopia; Solomon Gebre, Getachew Gari, Mesfin Sahle, Abde Aliy, Abebe Olani, Asegedech Sirak, Gizat Almaw, Getnet Mekonnen, Mekdes Tamiru, Sintayehu Guta, all from the National Animal Health Diagnostic and Investigation Centre, Ethiopia; James Wood, Andrew Conlan, Alan Clarke, all from Cambridge University, United Kingdom; Henrietta L. Moore and Catherine Hodge, both from University College London, United Kingdom; Constance Smith at University of Manchester, United Kingdom; R. Glyn Hewinson, Stefan Berg, Martin Vordermeier, Javier Nunez-Garcia, all from the Animal and Plant Health Agency, United Kingdom; Gobena Ameni, Berecha Bayissa, Aboma Zewude, Adane Worku, Lemma Terfassa, Mahlet Chanyalew, Temesgen Mohammed, Yemisrach Zeleke, all from Addis Ababa University, Ethiopia.

\section{Funding}

This work was supported by Armauer Hansen Research Institute (AHRI) and the Biotechnology and Biologic Sciences Research Council, the Department for International Development, the Economic \& Social Research Council, the Medical Research Council, the Natural Environment Research Council and the Defence Science \& Technology Laboratory, under the Zoonoses and Emerging Livestock Systems (ZELS) program, ref: BB/L018977/1.

\section{Disclosure}

The authors report no conflicts of interest for this work.

\section{References}

1. World Health Organization. Global Tuberculosis Report. Geneva, Switzerland: WHO; 2020 .

2. Ben Ayed H, Koubaa M, Marrakchi C, Rekik K, Hammami F. Extra pulmonary Tuberculosis: update on the Epidemiology, Ris k Factors and Prevention Strategies. Int J Trop Dis. 2018;1:006.

3. Biadglegne F, Tesfaye W, Anagaw B, et al. Tuberculosis lymphadenitis in Ethiopia. Jpn J Infect Dis. 2013;66(4):263-268. doi:10.7883/ yoken.66.263

4. Mittal N, Bansal P. Multidrug resistant extrapulmonary tuberculosis three case reports and review of literature. Internal Medicine Inside. 2014;2(1):1-4. doi:10.7243/2052-6954-2-2

5. Lohiya S, Tripathy JP, Sagili K, et al. Does drug-resistant extrapulmonary tuberculosis hinder TB elimination plans? A case from Delhi, India. Trop Med Int Health. 2020;5(3):109.

6. Coscolla M, Gagneux S. Consequences of genomic diversity in Mycobacterium tuberculosis. Semin Immunol. 2014;26(6):431-444.

7. Brites D, Gagneux S. The Nature and Evolution of Genomic Diversity in the Mycobacterium tuberculosis Complex. Adv Exp Med Biol. 2017;1019:1-26.

8. Firdessa R, Berg S, Hailu E, et al. Mycobacterial lineages causing pulmonary and extrapulmonary tuberculosis, Ethiopia. Emerg Infect Dis. 2013;19(3):460-463.

9. Brites D, Gagneux S. Co-evolution of Mycobacterium tuberculosis and Homo sapiens. Immunol Rev. 2015;264(1):6-24.

10. Mekonnen D, Derbie A, Chanie A, et al. Molecular epidemiology of M. tuberculosis in Ethiopia: a systematic review and meta-analysis. Tuberculosis. 2019;118:101858. doi:10.1016/j. tube. 2019.101858

11. Tulu B, Ameni G. Spoligotyping based genetic diversity of Mycobacterium tuberculosis in Ethiopia: a systematic review. $B M C$ Infect Dis. 2018;18(1):140. doi:10.1186/s12879-018-3046-4

12. Gygli SM, Borrell S, Trauner A, Gagneux S. Antimicrobial resistance in Mycobacterium tuberculosis: mechanistic and evolutionary perspectives. FEMS Microbiology Reviews. 2017;41(3):354-373. doi:10.1093/femsre/fux011

13. Koch A, Mizrahi V. Mycobacterium tuberculosis. Trends Microbiol. 2018;26(6):555-556. doi:10.1016/j.tim.2018.02.012

14. Vilchèze C, Jacobs JR. WR. Resistance to Isoniazid and Ethionamide in Mycobacterium tuberculosis: genes, Mutations, and Causalities. Microbiology Spectrum. 2014;2(4):Mgm2-0014-2013. doi:10.1128/ microbiolspec.MGM2-0014-2013

15. Zhang Y, Yew W. Mechanisms of drug resistance in Mycobacterium tuberculosis: update 2015. Int J Tuberc Lung Dis. 2015;19 (11):1276-1289. doi:10.5588/ijtld.15.0389

16. Parwati I, van Crevel R, van Soolingen D. Possible underlying mechanisms for successful emergence of the Mycobacterium tuberculosis Beijing genotype strains. Lancet Infect Dis. 2010;10 (2):103-111. doi:10.1016/S1473-3099(09)70330-5

17. Rufai SB, Sankar MM, Singh J, Singh S. Predominance of Beijing lineage among pre-extensively drug-resistant and extensively drug-resistant strains of Mycobacterium tuberculosis: a tertiary care center experience. Int J Mycobacteriol. 2016;5(Suppl 1):S197-s8. doi:10.1016/j.ijmyco.2016.07.005

18. Kamerbeek J, Schouls L, Kolk A, et al. Simultaneous detection and strain differentiation of Mycobacterium tuberculosis for diagnosis and epidemiology.. Journal of Clinical Microbiology. 1997;35 (4):907-914. doi:10.1128/JCM.35.4.907-914.1997

19. Demay C, Liens B, Burguière T, et al. SITVITWEB - a publicly available international multimarker database for studying Mycobacterium tuberculosis genetic diversity and molecular epidemiology. Infection, Genetics and Evolution. 2012;12(4):755-766. doi:10.1016/j.meegid.2012.02.004 
20. Aminian M, Shabbeer A, Bennett KP. A conformal Bayesian network for classification of Mycobacterium tuberculosis complex lineages. BMC Bioinformatics. 2010;11(S3):S4. doi:10.1186/14712105-11-S3-S4

21. Comas I, Homolka S, Niemann S, Gagneux S, Litvintseva AP. Genotyping of genetically monomorphic bacteria: DNA sequencing in Mycobacterium tuberculosis highlights the limitations of current methodologies. PLoS One. 2009;4(11):e7815. doi:10.1371/journal. pone.0007815

22. Gagneux S, Small PM. Global phylogeography of Mycobacterium tuberculosis and implications for tuberculosis product development Lancet Infect Dis. 2007;7(5):328-337. doi:10.1016/S1473-3099(07) 70108-1

23. Biadglegne F, Tessema B, Rodloff AC, Sack U. Magnitude of Gene Mutations Conferring Drug Resistance in Mycobacterium Tuberculosis Isolates from Lymph Node Aspirates in Ethiopia. Int J Med Sci. 2013;10(11):1589-1594. doi:10.7150/ijms.6806

24. Biadglegne F, Tessema B, Sack U, Rodloff AC. Drug resistance of Mycobacterium tuberculosis isolates from tuberculosis lymphadenitis patients in Ethiopia. Int.J.Med. 2014;140(1):116-122.

25. Bekele S, Derese Y, Hailu E, et al. Line-probe assay and molecular typing reveal a potential drug resistant clone of Mycobacterium tuberculosis in Ethiopia. Trop Dis Travel Med Vaccines. 2018;4 (1):15. doi:10.1186/s40794-018-0075-3

26. Lobie TA, Woldeamanuel Y, Asrat D, Beyene D, Bjørås M, Aseffa A. Genetic diversity and drug resistance pattern of Mycobacterium tuberculosis strains isolated from pulmonary tuberculosis patients in the Benishangul Gumuz region and its surroundings, Northwest Ethiopia. PLoS One. 2020;15(4):e0231320. doi:10.1371/journal. pone. 0231320

27. Tilahun M, Shimelis E, Wogayehu T, et al. Molecular detection of multidrug resistance pattern and associated gene mutations in M. tuberculosis isolates from newly diagnosed pulmonary tuberculosis patients in Addis Ababa, Ethiopia. PLoS One. 2020;15(8): e0236054. doi:10.1371/journal.pone.0236054

28. Zewdie O, Mihret A, Abebe T, et al. Genotyping and molecular detection of multidrug-resistant Mycobacterium tuberculosis among tuberculosis lymphadenitis cases in Addis Ababa, Ethiopia. New Microbes New Infect. 2018;21:36-41. doi:10.1016/j.nmni.201 7.10.009

29. Tadesse M, Aragaw D, Dimah B, et al. Drug resistance-conferring mutations in Mycobacterium tuberculosis from pulmonary tuberculosis patients in Southwest Ethiopia. Int $J$ Microbiol. 2016;5 (2):185-191.

30. Damena D, Tolosa S, Hailemariam M, et al. Genetic diversity and drug susceptibility profiles of Mycobacterium tuberculosis obtained from Saint Peter's TB specialized Hospital, Ethiopia. PLoS One. 2019;14(6):e0218545. doi:10.1371/journal.pone.0218545

31. Kigozi E, Kasule GW, Musisi K, et al. Prevalence and patterns of rifampicin and isoniazid resistance conferring mutations in Mycobacterium tuberculosis isolates from Uganda. PLoS One. 2018;13(5):e0198091. doi:10.1371/journal.pone.0198091

32. Alelign A, Zewude A, Mohammed T, Tolosa S, Ameni G, Petros B. Molecular detection of Mycobacterium tuberculosis sensitivity to rifampicin and isoniazid in South Gondar Zone, northwest Ethiopia. BMC Infect Dis. 2019;19(1):343. doi:10.1186/s12879-019-3978-3

33. Bedewi Omer Z, Mekonnen Y, Worku A, et al. Evaluation of the GenoType MTBDRplus assay for detection of rifampicin- and isoniazid-resistant Mycobacterium tuberculosis isolates in central Ethiopia. Int J Mycobacteriol. 2016;5(4):475-481. doi:10.1016/j. ijmyco.2016.06.005

34. Siddiqui S, Brooks MB, Malik AA, et al. Evaluation of GenoType MTBDRplus for the detection of drug-resistant Mycobacterium tuberculosis on isolates from Karachi, Pakistan. PLoS One. 2019;14 (8):e0221485. doi:10.1371/journal.pone.0221485
35. Fenner L, Egger M, Bodmer T, et al. Effect of Mutation and Genetic Background on Drug Resistance in Mycobacterium tuberculosis. Antimicrobial Agents and Chemotherapy. 2012;56(6):3047-3053. doi:10.1128/AAC.06460-11

36. Shin SS, Modongo C, Baik Y, et al. Mixed Mycobacterium tuberculosis-Strain Infections Are Associated With Poor Treatment Outcomes Among Patients With Newly Diagnosed Tuberculosis, Independent of Pretreatment Heteroresistance.. The Journal of Infectious Diseases. 2018;218(12):1974-1982. doi:10.1093/infdis/jiy480

37. Hofmann-Thiel S, van Ingen J, Feldmann K, et al. Mechanisms of heteroresistance to isoniazid and rifampin of Mycobacterium tuberculosis in Tashkent, Uzbekistan. European Respiratory Journal. 2008;33(2):368. doi:10.1183/09031936.00089808

38. Tadesse M, Abebe G, Bekele A, et al. The predominance of Ethiopian specific Mycobacterium tuberculosis families and minimal contribution of Mycobacterium bovis in tuberculous lymphadenitis patients in Southwest Ethiopia. Infection, Genetics and Evolution. 2017;55:251-259. doi:10.1016/j.meegid.2017.09.016

39. Garedew L, Mihret A, Abebe T, Ameni G. Molecular typing of mycobacteria isolated from extrapulmonary tuberculosis patients at Debre Birhan Referral Hospital, central Ethiopia. Scandinavian Journal of Infectious Diseases. 2013;45(7):512-518. doi:10.3109/ 00365548.2013 .773068

40. Biadglegne F, Merker M, Sack U, Rodloff AC, Niemann S, Mokrousov I. Tuberculous Lymphadenitis in Ethiopia Predominantly Caused by Strains Belonging to the Delhi/CAS Lineage and Newly Identified Ethiopian Clades of the Mycobacterium tuberculosis Complex. PLoS One. 2015;10(9): e0137865. doi:10.1371/journal.pone.0137865

41. Korma W, Mihret A, Hussien J, Anthony R, Lakew M, Aseffa A. Clinical, molecular and drug sensitivity pattern of mycobacterial isolates from extra-pulmonary tuberculosis cases in Addis Ababa, Ethiopia. BMC Infect Dis. 2015;15(1):456. doi:10.1186/s12879-015-1177-4

42. Wondale B, Keehwan K, Medhin G, et al. Molecular epidemiology of clinical Mycobacterium tuberculosis complex isolates in South Omo, Southern Ethiopia. BMC Infect Dis. 2020;20(1):750. doi:10.1186/ s12879-020-05394-9

43. Belay M, Ameni G, Bjune G, Couvin D, Rastogi N, Abebe F. Strain Diversity of Mycobacterium tuberculosis Isolates from Pulmonary Tuberculosis Patients in Afar Pastoral Region of Ethiopia. Biomed Res Int. 2014;2014:238532. doi:10.1155/2014/238532

44. Yimer SA, Norheim G, Namouchi A, et al. Mycobacterium tuberculosis Lineage 7 Strains Are Associated with Prolonged Patient Delay in Seeking Treatment for Pulmonary Tuberculosis in Amhara Region, Ethiopia. Microbiol Infect Dis. 2015;53(4):1301.

45. Yimer SA, Hailu E, Derese Y, Bjune GA, Holm-Hansen C. Spoligotyping of Mycobacterium tuberculosis isolates among pulmonary tuberculosis patients in Amhara Region, Ethiopia. APMIS. 2013;121(9):878-885. doi:10.1111/apm.12046

46. Blouin Y, Hauck Y, Soler C, et al. Significance of the identification in the Horn of Africa of an exceptionally deep branching Mycobacterium tuberculosis clade. PLoS One. 2012;7(12):e52841. doi:10.1371/journal.pone.0052841

47. Nebenzahl-Guimaraes H, Yimer SA, Holm-Hansen C, de Beer J, Brosch R, van Soolingen D. Genomic characterization of Mycobacterium tuberculosis lineage 7 and a proposed name: 'Aethiops vetus'.. Microb Genom. 2016;2(6):e000063-e. doi:10.1099/mgen.0.000063

48. Comas I, Hailu E, Kiros T, et al. Population Genomics of Mycobacterium tuberculosis in Ethiopia Contradicts the Virgin Soil Hypothesis for Human Tuberculosis in Sub-Saharan Africa. Curr Biol. 2015;25(24):3260-3266. doi:10.1016/j.cub.2015.10.061

49. Zewdie O, Mihret A, Ameni G, Worku A, Gemechu T, Abebe T. Molecular typing of mycobacteria isolated from tuberculous lymphadenitis cases in Addis Ababa, Ethiopia. Int J Tuberc Lung Dis. 2016;20(11):1529-1534. doi:10.5588/ijtld.15.1023 
50. Ei PW, Aung WW, Lee JS, Choi G-E, Chang CL. Molecular Strain Typing of Mycobacterium tuberculosis: a Review of Frequently Used Methods. J Korean Med Sci. 2016;31(11):1673-1683. doi:10.3346/ jkms.2016.31.11.1673

51. Agonafir M, Lemma E, Wolde-Meskel D, et al. Phenotypic and genotypic analysis of multidrug-resistant tuberculosis in Ethiopia.. Int J Tuberc Lung Dis. 2010;14(10):1259-1265.

52. Diriba B, Berkessa T, Mamo G, Tedla Y, Ameni G. Spoligotyping of multidrug-resistant Mycobacterium tuberculosis isolates in Ethiopia. Int J Tuberc Lung Dis. 2013;17(2):246-250. doi:10.5588/ijtld.1 2.0195
53. Bedewi Z, Mekonnen Y, Worku A, et al. Mycobacterium tuberculosis in central Ethiopia: drug sensitivity patterns and association with genotype. New Microbes and New Infections. 2017;17:69-74. doi:10.1016/j.nmni.2017.02.003

54. Kidenya BR, Webster LE, Behan S, et al. Epidemiology and genetic diversity of multidrug-resistant tuberculosis in East Africa. Tuberculosis. 2014;94(1):1-7. doi:10.1016/j.tube.2013.08.009

\section{Publish your work in this journal}

Infection and Drug Resistance is an international, peer-reviewed openaccess journal that focuses on the optimal treatment of infection (bacterial, fungal and viral) and the development and institution of preventive strategies to minimize the development and spread of resistance. The journal is specifically concerned with the epidemiology of antibiotic resistance and the mechanisms of resistance development and diffusion in both hospitals and the community. The manuscript management system is completely online and includes a very quick and fair peerreview system, which is all easy to use. Visit http://www.dovepress.com/ testimonials.php to read real quotes from published authors. 